\title{
Analisis produktivitas tenaga kerja sektor pertanian di Sumatera
}

\author{
Awina Oktavia; Zulfanetti; Yulmardi* \\ Prodi Ekonomi Pembangunan, Fakultas Ekonomi dan Bisnis, Universitas Jambi \\ *E-mail korespondensi:yulmardi@unja.ac.id
}

\begin{abstract}
The aims of this study was to analyze the effect of education and the exchange rate of farmers on the level of labor productivity in the agricultural sector in Sumatra. The data used is panel data of provinces in Sumatra during 2010-2014. The analysis used a panel data regression model. The results showed that education had significant positive effect, while the farmer exchange rate had a significant negative effect on the level of agricultural sector labor productivity in Sumatra.
\end{abstract}

Keywords: Education, Farmer Exchange Rates, Labor, Labor Productivity, Agriculture Sector.

\begin{abstract}
Abstrak
Tujuan penelitian ini adalah untuk menganalisis pengaruh pendidikan dan nilai tukar petani terhadap tingkat produktivitas tenaga kerja sektor pertanian di Sumatera. Data yang digunakan adalah data panel provinsi-provinsi di Sumatera selama Tahun 20102014. Analisis menggunakan model regresi data panel. Hasil penelitian menunjukkan bahwa pendidikan berpengaruh positif signifikan, sedangkan nilai tukar petani berpengaruh negatif signifikan terhadap tingkat produktivitas tenaga kerja sektor pertanian di Sumatera.
\end{abstract}

$\overline{\text { Kata kunci : Pendidikan, Nilai Tukar Petani, Tenaga Kerja, Produktivitas Tenaga }}$ Kerja, Sektor Pertanian.

\section{PENDAHULUAN}

Pembangunan suatu bangsa memerlukan aset pokok yang disebut sumber daya (resources), baik sumber daya alam (natural resources), maupun sumber daya manusia(human resources). Kedua sumber daya tersebut sangat penting dalam menentukan keberhasilan suatu pembangunan. (Notoadmodjo, 2003)

Sumber daya manusia (SDM) merupakan modal dan kekayaan yang terpenting dari setiap kegiatan manusia. Manusia sebagai unsur terpenting mutlak dianalisis dan dikembangkan dengan cara tersebut. Waktu, tenaga dan kemampuannya benar-benar dapat dimanfaatkan secara optimal bagi kepentingan organisasi, maupun bagi kepentingan individu. Sebagai faktor pertama dan utama dalam proses pembangunan, SDM selalu menjadi subjek dan objek pembangunan. Tingkat produktivitas tenaga kerja memegang peranan yang sangat penting dalam pertumbuhan ekonomi nasional, dimana pendapatan nasional maupun daerah banyak diperoleh dengan cara meningkatkan kualitas SDM.

Dalam masyarakat modern seperti sekarang ini, terlebih lagi dalam era globalisasi kita dituntut untuk mampu menghadapi persaingan yang komprehensif baik didalam maupun diluar negeri. Salah satu cara untuk mengantisipasi persaingan yang makin kompetitif tersebut adalah dengan meningkatkan kualitas sumberdaya manusia yang komprehensif. Kesehatan dan pendidikan memiliki peranan penting untuk mengukur 
kualitas SDM.Pendidikan merupakan kebutuhan dasar manusia, karena melalui pendidikan dapat membuat manusia menjadi berpengetahuan. Disisi lain, pendidikan merupakan suatu bentuk invesasi nasional untuk meningkatkan kualitas sumberdaya manusia menjadi lebih produktif sesuai dengan yang dibutuhkan dalam pertumbuhan ekonomi modern. Pendidikan juga merupakan investasi SDM yang penting disamping modal fisik. Dengan adanya investasi pendidikan diharapkan menghasilkan suatu peningkatan kesejahteraan dan kesempatan yang lebih luas dalam kehidupan nyata.Perlu diketahui pentingnya investasi dalam hal pendidikan memerlukan peran pemerintah guna membangun sarana dan sistem pendidikan yang baik.

SDM bersama-sama dianggap sebagai keunggulan kompetitif untuk menjadikan SDM sebagai tenaga ahli dalam mengejar ketertinggalan dari pembangunan ekonomi. Meskipun kemajuan teknologi mempunyai peranan penting dalam mendorong pertumbuhan ekonomi, tetapi dalam pembuatan kebijakan pembangunan teknologi itu sendiri harus mempertimbangkan antara lain sumber daya yang dimiliki, masalahmasalah yang dihadapi dan tujuan pembangunan itu sendiri. (Subri, 2003)

Sebagai Negara agraris dan maritim, Indonesia mempunyai keunggulan komparatif. Kegiatan ekonomi yang memanfaatkan keunggulan komparatif selama ini telah berkembang di Indonesia dalam pembanguan pertanianyang merupakan salah satu sub-siatem agribisnis. Strategi pembangunan sistem agri bisnis yang antara lain berbasis pada pendayaagunaan keragaman sumber daya yang ada disetiap daerah, tidak terlalu mengandalkan impor dan pinjaman luar negri. (Lembaga Informasi Nasional, 2001).

Sektor pertanian merupakan salah satu faktor yang membangun perekonomian Indonesia disamping sektor-sektor lainnya. Disatu sisi, peran sektor pertanian bagi penduduk Indonesia sangat besar, antara lain memberikan nilai tambah yang besar bagi perekonomian, menampung sebagian besar tenaga kerja Indonesia. (Badan Pusat Statistik, 2013).

Di dalam pembangunan pertanian, peran SDM itu sendiri mendapatkan perhatian secara khusus karena SDM memiliki peran penting dalam pembangunan Nasional melalui jumlah dan kualitas penduduk.Jumlah penduduk yang besar merupakan pasar potensial untuk memasarkan hasil-hasil produksi, sementara kualitas penduduk menentukan besarnya produktivitas yang ada. Tanpa kualitas SDM yang baik, maka kegiatan ekonomi di sektor apapun termasuk sektor pertanian tidak akan mampu berjalan sesuai dengan tujuan yang ingin dicapai. Karena dalam proses untuk menghasilkan output yang baik dibutuhkan tingkat produktivitas yang tinggi dan sebagai penopang tingginya tingkat produktivitas diperlukan kualitas sumber daya yang baik pula yang salah satunya dapat dilihat dari tingkat pendidikan yang dimiliki. Alasan pentingnya tingkat pendidikan dalam peningkatan sumber daya manusia yaitu agar manusia mampu berfikir kreatif dan inovatif baik dalam memutuskan kebijakan dalam dunia kerja dan dalam proses menghasilkan output produksi.

Berdasarkan hal tersebut maka penelitian ini bertujuan untuk menganalisis pengaruh tingkat pendidikan dan nilai tukar petani terhadap produktivitas tenaga kerja sektor pertanian di Sumatera

\section{TINJAUAN PUSTAKA}

Produksi adalah kegiatan yang mentransformasikan masukan (input) menjadi keluaran (output), tercakup semua aktivitas atau kegiatan yang menghasilkan barang atau jasa, serta kegiatan-kegiatan lain yang mendukung atau menunjang usaha untuk menghasilkan produk tersebut yang berupa barang-barang atau jasa. (Assauri, 2008).

Teori produksi dalam ilmu ekonomi membedakan analisisnya kepada dua pendekatan berikut (Sukirno, 2013) :

a. Teori produksi dengan satu faktor berubah 
Teori produksi yang sederhana menggambarkan tentang hubungan di antara tingkat produksi suatu barang dengan jumlah tenaga kerja yang digunakan untuk menghasilkan berbagai tingkat produksi barang tersebut. Dalam analisis ini faktorfaktor produksi lain dianggap tetap jumlahnya yaitu modal, tanah dan teknologi.

b. Teori produksi dengan dua faktor peubah

Dalam analisis ini dimisalkan terdapat dua jenis faktor produksi yang dapat diubah jumlahnya yaitu tenaga kerja dan modal dimana kedua faktor produksi tersebut dapat dipertukar-tukarkan penggunaannya.

Secara umum yang dimaksud dengan produktivitas kerja adalah perbandingan antara hasil yang dicapai (output)dengan keseluruhan sumber daya yang digunakan (input). Konsep produktivitas dikembangkan untuk mengukur besarnya kemampuan menghasilkan nilai tambah atas komponen masukan yang digunakan. Pada dasarnya produktivitas mencakup sikap mental patriotik yang memandang hari depan secara optimis dengan berakhir pada keyakinan diri. Dalam doktrin pada konferensi Oslo 1984, defenisi umum produktivitas adalah suatu konsep yang bersifat universal yang bertujuan untuk menyediakan lebih banyak manusia dengan menggunakan sumber-sumber riil yang makin sedikit.(Sinungan, 2009).

Konsep produktivitas secara sederhana adalah rasio jumlah output riil dengan faktor input sehingga pengertian untuk produktivitas tenaga kerja adalah rasio jumlah output riil dengan jumlah tenaga kerja yang digunakan untuk menghasilkan jumlah output tersebut. Pada teori produktivitas marginal tenaga kerja terdapat dua asumsi yang dipakai, yaitu :

1. Ada kecenderungan dari pemilik perusahaan untuk menyewa tenaga kerja lebih banyak bila tambahan satu orang tenaga kerja masih dapat menambah pendapatan perusahaan yang lebih besar.

2. Pemilik perusahaan akan menyewa jumlah tenaga kerja (penggunaan optimum tenaga kerja) diperpotongan Marginal Revenue Product OF Labour $\left(\mathrm{MRP}_{\mathrm{L}}\right)$ dan biaya tenaga kerja (upah). (Feriyanto, 2014)

Pertanian adalah kegiatan pemanfaatan sumber daya hayati yang dilakukan manusia untuk menghasilkan bahan pangan, bahan baku industri, atau sumber energi, serta untuk mengelola lingkungan hidupnya. Sejak awal dikembangkannya pertanian di bumi ini, konsep pertamanya adalah pemenuhan kebutuhan pangan manusia.Pertanian adalah suatu bentuk produksi yang khas, yang didasarkan pada peoses pertumbuhan tanaman dan hewan.Petani mengelola dan merangsang pertumbuhan tanaman dalam suatu usaha tani, dimana kegiatan produksi merupakan bisnis, sehingga pengeluaran dan pendapatan sangat penting artinya.(Mosher, 1966).

Menurut Kuzhnets, sektor pertanian mengkontribusikan terhadap pertumbuhan dan pembangunan ekonomi nasional dalam 4 bentuk, yaitu (1) kontribusi produk, (2) kontribusi pasar, (3) kontribusi faktor-faktor produksi, (4) kontribusi devisa.

Pendidikan lebih dari pengajaran/pembelajaran, karena pengajaran sebagai suatu proses transfer ilmu belaka, sedang pendidikan merupakan transformasi nilai dan pembentukan kepribadian dengan segala aspek yang dicakupnya. Fungsi dan peranan sosial kemanusiaan pendidikan merujuk pada kontribusi pendidikan terhadap perkembangan manusia dan hubungan sosial pada berbagai tingkat sosial yang berbeda.Orang yang berpendidikan diharapkan lebih mengerti hak dan kewajibannya sehingga wawasan dan perilakunya semakin demokratis. (Hidayat, 2013) .

Unsur penting yang dijadikan sebagai indikator kesejahteraan petani adalah besarnya pendapatan dan perimbangannya dengan pengangguran.Penanda kesejahteraan yang unik bagi rumahtanggatani praktis tidak ada, sehingga NTP menjadi pilihan satusatunya bagi pengamat pembangunan pertanian dalam menilai tingkat kesejahteraan petani.Dengan demikian, NTP merupakan salah satu indikator relatif tingkat 
kesejahteraan petani.Semakin tinggi NTP, relatif semakin sejahtera tingkat kehidupan petani.(Simatupang dan Maulana, 2008).

\section{METODE PENELITIAN}

\section{Jenis dan sumber data}

Data yang digunakan dalam penelitian ini adalah data sekunder, berupa data produktivitas tenaga kerja sektor pertanian, pendidikan dan nilai tukar petani pada provinsi-provinsi di Sumatera selama periode tahun 2010 - 2014. Sumber utama data adalah Badan Pusat Statistik baik di tingkat pusat maupun provinsi.

\section{Analisis data} berikut:

Analisis data menggunakan model regresi data panel dengan persamaan sebagai

$$
\text { PVTK }_{\text {it }}=\beta_{0}+\beta_{1} \text { PDK }_{1 \text { it }}+\beta_{2} \mathrm{NTP}_{2 \text { it }}+\varepsilon_{\text {it }}
$$

Dimana :

$$
\begin{array}{ll}
\text { PVTK } & =\text { Produktivitas Tenaga Kerja } \\
\beta_{0} & =\text { Konstanta } \\
\text { PDK } & =\text { Tingkat Pendidikan yang ditamatkan } \\
\text { UMP } & =\text { Nilai tukar petani } \\
\varepsilon_{i t} & =\text { Kesalahan pengganggu } \\
i & =\text { Entitas ke- } i \text { (10 provinsi di Sumatera }) \\
t & =\text { Periode tahun ke- } t(2010-2014)
\end{array}
$$

Ada tiga metode yang biasa digunakan untuk mengestimasi model regresi dengan data panel (Widarjono, 2007) :

1. Koefisien tetap antar waktu dan individu (Common Effect)

Model common effect merupakan pendekatan data panel yang paling sederhana. Model ini tidak memperhatikan dimensi individu maupun waktu sehinnga diasumsikan bahwa perilaku antar individu sama dalam berbagai kurun waktu.

2. Slope konstan tetapi intersep berbeda antar individu (Fixed Effect)

Pendekatan model Fixed Effect mengasumsukan bahwa intersep dari setiap individu adalah berbeda sedangkan slope antar individu adalah tetap. Teknik model Fixed Effect adalah teknik mengestimasi data panel dengan menggunakan variabel dummy untuk menangkap adanya intersep

3. Estimasi dengan pendekatan Random Effect

Metode Random Effect mampu mengatasi masalah degree of freedom yang dapat mengurangi efisiensi parameter dengan menggunakan variabel gangguan (error terms).Model Random Effect mengestimasi data panel dimana variabel gangguan mungkin saling berhubungan antar waktu dan antar individu.

Selanjutnya dalam rangka pemilihan model (teknik estimasi) terbaik dilakukan pengujian-pengujian sebagai berikut:

1. Uji Statistik F (Chow)

Untuk mengetahui model mana yang lebih baik dalam pengujian data panel bisa dilakukan dengan penambahan variabel dummy sehingga dapat diketahui bahwa intersepnya berbeda dapat di uji dengan uji Statistik F. Uji ini digunakan untuk mengetahui apakah teknik regresi data panel dengan metode Fixed Effect leih baik dari regresi model data panel tanpa variabel dummy atau metode Common Effect. Nilai 
statistik $\mathrm{F}$ hitung akan mengikuti distribusi statistik $\mathrm{F}$ derajat kebebasan (degree of freedom) sebanyak $m$ untuk numerator dan sebanyak $n$ - $k$ untuk denumerator.

2. Uji Hausman

Uji Hausman dapat didefenisikan swbagai pengujian statistic untuk memilih apakah model Fixed Effect atau Random Effect yang paling tepat digunakan. Statistic Uji Hausman ini mengikuti distribusi statistic Chi Square dengan degree of freedom sebanyak $k$ dimana $k$ adalah jumlah variabel independent.

Untuk mengikuti distribusi statistik chi-square dengan derajat bebas sebanyak jumlah peubah bebas.Hipotesis nol ditolak jika nilai statistik Hausman lebih besar daripada nilai kritis statistik chi-square. Ini berarti bahwa model yang tepat untuk regresi data panel adalah metode fixed effect. (Juanda dan Junaidi, 2012).

3. Uji Lagrange Multiplier

Uji ini digunakan untuk mengetahui apakah model Random Effect atau model Common Effect yang paling tepat untuk digunakan. Uji LM ini didasarkan pada distribusi Chi-Squares dengan derajat kebebasan (df) sebesar jumlah variabel independent.

\section{Operasional Variabel}

1. Produktivitas tenaga kerja adalah tingkat kemampuan tenaga kerja dalam menghasilkan produk . Produktivitas tenaga kerja menunjukkan adanya kaitan antara output (hasil kerja) dengan waktu yang dibutuhkan untuk menghasilkan produk dari seorang tenaga kerja periode 2010-2014 dalam satuan persen.

2. Tingkat pendidikan adalah suatu kondisi jenjang pendidikan yang dimiliki oleh sesorang melalui pendidikan formal yang diukur dari rata-rata lama sekolah penduduk masing-masing provinsi pada periode 2010-2014.:

3. Nilai Tukar Petani (NTP) adalah perbandingan antara indeks harga yang diterima petani (It) dengan indeks harga yang dibayar petani (Ib) yang dinyatakan dalam persentase

\section{HASIL DAN PEMBAHASAN}

\section{Perkembangan produktivitas tenaga kerja, pendidikan, nilai tukar petani provinsi-provinsi di Sumatera}

Peningkatan produktivitas tenaga kerja merupakan sasaran yang paling strategis karena mampu meningkatkan produktivitas faktor produksi lainnya seperti modal, bahan baku, energi, dan lainnya. Perkembangan produktivitas tenaga kerja sektor pertanian masing-masing provinsi di Sumatera cenderung mengalami peningkatan meskipun ada beberapa provinsi yang justru mengalami mengalami penurunan. Ratarata perkembangan produktivitas tenaga kerja sektor pertanian di Sumatera periode tahun 2010-2014 adalah sebesar 6,15 persen. Dengan perkembangan produktivitas tenaga kerja sektor pertanian tertinggi di Sumatera terdapat di Provinsi Lampung yaitu sebesar 12,11 persen. Kemudian perkembangan produktivitas tertinggi kedua terdapat di Provinsi Sumatera Selatan yaitu sebesar 11,22 persen. Sedangkan perkembangan tingkat produktivitas tenaga kerja sektor pertanian terendah terdapat di Provinsi Nanggore Aceh Darussalam yaitu sebesar 1,81 persen.

Secara keseluruhan, rata-rata lama pendidikan yang ditamatkan oleh tenaga kerja sektor pertanian masih tergolong rendah.Keadaan ekonomi yang kurang mampu untuk membayar sejumlah biaya pendidikan dan banyak masyarakat yang masih berasumsi bahwa pendidikan bukan merupakan kebutuhan yang prioritas. 
Rata-rata lama sekolah yang ditamatkan oleh tenaga kerja sektor pertanian di Sumatera tidak mengalami perubahan yang fluktuatif dimana kondisi pendidikan yang ditamatkan tenaga kerja sektor pertanian cenderung tetap yaitu hanya setara dengan tamat SD (6 tahun). Pada tahun 2010 adalah selama 6,39 tahun, pada tahun 2011 meningkat menjadi selama 6,44 tahun, kemudian pada tahun 2012 menjadi selama 6,62 tahun dan pada tahun 2013 menjadi selama 6,65 dan kemudian pada tahun 2014 angka tersebut menurun menjadi selama 6,59 tahun.

Salah satu indikator tingkat kesejahteraan petani adalah nilai tukar petani (NTP). Besar kecilnya proporsi pendapatan rumah tangga petani dari sektor pertanian akan mempengaruhi besar kecilnya kekuatan nilai tukar pertanian bagi petani yang berkaitan erat dengan peran pertanian dalam pemenuhan kebutuhan rumah tangga petani. Tenaga kerja sektor pertanian yang paling sejahtera dibandingkan provinsi-provinsi yang ada di Sumatera selama periode penelitian adalah Provinsi Lampung. Nilai tukar petani di Provinsi Lampung sebesar 115,04 pada tahun 2010 kemudian meningkat pada tahun 2011 menjadi sebesar 121,49 persen dan meningkat lagi menjadi sebesar 125,42 persen pada tahun 2012. Namun pada tahun 2013 mengalami penurunan menjadi sebesar 124,70 dan kemudian menurun lagi menjadi sebesar 104,18 pada tahun 2014.

\section{Pengaruh pendidikan dan nilai tukar petani terhadap produktivitas tenaga kerja sektor pertanian}

Berdasarkan uji statistik F (Chow), uji Hausman dan uji Lagrange Multiplier, diperoleh bahwa model regresi data panel terbaik dalam memprediksi produktivitas tenaga kerja sektor pertanian di Sumatera adalah model random effect. Hasil estimasi model diberikan sebagai berikut:

$\begin{array}{llll}\text { PVTK }_{\text {it }} & =3,08+ & 12,55 \mathrm{PDDK}_{\mathrm{it}}-0,41 \mathrm{NTP}_{\mathrm{it}} \\ \text { Std. error } & =(34,51) & (4,43) & (0,19) \\ \mathrm{t}_{\text {-stat }} & =(0,08) & (2,83) & (-2,14) \\ \mathrm{R}^{2} & =0,20 & & \\ \mathrm{~F} & =6,0132 & & \end{array}$

Tabel 1. Nilai intersep random effect provinsi-provinsi di Sumatera

\begin{tabular}{clc}
\hline No & \multicolumn{1}{c}{ Provinsi } & Nilai Intersep \\
\hline 1 & NAD & -16.39 \\
2 & Sumatera Utara & -15.51 \\
3 & Sumatera Barat & -2.44 \\
4 & Riau & 49.53 \\
5 & Jambi & -6.765 \\
6 & Sumatera Selatan & -15.92 \\
7 & Bengkulu & -18.67 \\
8 & Lampung & -1.86 \\
9 & Bangka Belitung & 13.53 \\
10 & Kepulauan Riau & 14.52 \\
\hline
\end{tabular}

\section{Uji Hipotesis}

Berdasarkan hasil analisis, diperoleh nilai F-hitung sebesar 6.013205 dan nilai probabilitas $\mathrm{F}$ sebesar 0.004728.Dalam taraf signifikansi $5 \%$ maka uji $\mathrm{F}$ signifikan.Maka dapat disimpulkan bahwa pendidikan dan nlai tukar petani secara bersama-sama berpengaruh sifnifikan terhadap produktivitas tenaga kerja sektor pertanian. 
Hasil analisis uji parsial menunjukkan masing-masing variabel bebas secara individual berpengaruh signifikan terhadap variabel terikat.

a. Pengaruh pendidikan terhadap produktivitas tenaga kerja sektor pertanian. Hasil analisis menunjukkan bahwa nilai t-hitung pendidikan sebesar 2.83 dan nilai probabilitasnya sebesar 0.0068. Dalam taraf signifikansi $1 \%$, maka dapat disimpulkan bahwa secara individu pendidikan berpengaruh signifikan terhadap produktivitas tenaga kerja sektor pertanian.

b. Nilai tukar petani. Hasil analisis menunjukkan bahwa nilai t-hitung dari nilai tukar petani sebesar -2.143551 dan nilai probabilitasnya sebesar 0.0373. Dalam taraf signifikansi $5 \%$, maka dapat disimpulkan bahwa secara individu nilai tukar petani berpengaruh signifikan terhadap produktivitas tenaga kerja sektor pertanian.

\section{Interpretasi hasil}

Berdasarkan hasil estimasi, dapat dikemukakan bahwa tingkat pendidikan yang ditamatkan oleh tenaga kerja sektor pertanian di Sumatera mempunyai pengaruh positif dan signifikan terhadap produktivitas tenaga kerja sektor pertanian. Dengan kata lain, semakin tinggi tingkat pendidikan yang ditamatkan oleh tenaga kerja sektor pertanian maka tingkat produktivitas tenaga kerja sektor pertanian juga akan meningkat.

Nilai koefisien dari pendidikan yaitu sebesar 12,55 persen hal ini menunjukkan jika tingkat pendidikan yang ditamatkan oleh tenaga kerja sektor pertanian naik sebesar 1 persen maka produktivitas tenaga kerja sektor pertanian akan naik sebesar 12,55 persen dengan asumsi bahwa variabel lain dianggap tetap.

Nilai tukar petani berpengaruh negatif terhadap tingkat produktivitas tenaga kerja sektor pertanian provinsi-provinsi di Sumatera. Nilai koefisien dari nilai tukar petani yaitu sebesar -0,41 yang artinya jika nilai tukar petani naik sebesar 1 persen maka produktivitas tenaga kerja sektor pertanian akan turun sebesar $-0,41$ persen dengan asumsi bahwa variabel lain dianggap tetap.

Pengaruh negatif nilai tukar petani terhadap produktivitas tenaga kerja mengindikasikan bahwa ketika harga produk pertanian (harga yang diterima petani) meningkat relatif lebih tinggi dibandingkan harga produk non-pertanian (harga yang dibayar petani), berdampak pada berkurangnya intensitas petani dalam aktivitas produksi pertaniannya, sehingga mengurangi produktivitas tenaga kerjanya.

\section{KESIMPULAN DAN SARAN}

\section{Kesimpulan}

Rata-rata perkembangan produktivitas tenaga kerja sektor pertanian di Sumatera selama periode tahun 2010-2014 adalah sebesar 6,15 persen. Secara simultan, pendidikan dan nilai tukar petani berpengaruh signifikan terhadap produktivitas tenaga kerja sektor pertanian di Sumatera. Secara parsial, pendidikan mempunyai pengaruh positif signifikan, sedangkan nilai tukar petani mempunyai pengaruh negatif signifikanterhadap produktivitas tenaga kerja sektor pertanian di Sumatera.

\section{Saran}

Untuk meningkatkan kualitas sumberdaya manusia agar terciptanya produktivitas tenaga kerja khususnya pada sektor pertanian di Sumatera, sudah seharusnya pihak pemerintah untuk lebih memperhatikan dan meningkatkan kualitas baik sarana maupun prasarana pendidikan formal dan informal yang lebih memadai agar masyarakat dapat melanjutkan pendidikan dengan baik dan maksimal sehingga menghasilkan tenaga kerja yang terdidik dan terlatih. 


\section{DAFTAR PUSTAKA}

Anonim. 2001. Agribisnis di Indonesia. Jakarta : Direktorat Pengelolaan Informasi Perekonomian Lembaga Informasi Nasional.

BPS.2013. Analisis Sosial Ekonomi Petani Indonesia.Jakarta : Badan Pusat Statistik.

Feriyanto, Nur. 2014. Ekonomi Sumber Daya Manusia : Dalam Perspektif Indonesia. UPP STIM YKPN. Yogyakarta.

Hasibuan, Melayu. 1996. Organisasi Dan Motivasi, Dasar Peningakatan Produktivitas. Jakarta : Bumi Aksara Putra

Hidayat, Syarif. 2013. Teori dan Prinsip Pendidikan. PT Pustaka Mandiri.Tangerang. Juanda, Junaidi. 2012. Ekonometrika Deret Waktu : Teori dan Aplikasi. IPB PRESS Junaidi, J., Amir, A., \& Hardiani, H. (2014). Potensi Klaster Agroindustri Usaha Mikro Kecil dan Menengah di Provinsi Jambi. Jurnal Perspektif Pembiayaan dan Pembangunan Daerah, 2(1), 9-20.

Junaidi,J; Zulgani,Z. (2011). Peranan Sumberdaya Ekonomi dalam Pembangunan Ekonomi Daerah. Jurnal Pembangunan Daerah, Edisi 3, 27-33

Junaidi,J; Zulfanetti,Z. (2016). Analisis Kondisi dan Proyeksi Ketenagakerjaan di Provinsi Jambi. Jurnal Perspektif Pembiayaan dan Pembangunan Daerah, 3(3), 141-150

Notoadmodjo, Soekidjo.1998. Pengembangan Sumber Daya Manusia. Jakarta : PT Rineka Cipta.

Sinungan, Muchdarsyah. 2009. Produktivitas. Jakarta : Bumi Aksara

Subri, Mulyadi. 2003. Ekonomi Sumber Daya Manusia. Divisi Buku Perguruan Tinggi. Raja Grafinda Persada,

Winarno, Wing Wahyu. 2007. Analisis Ekonometrika dan Statistika dengan EViews. Edisi Kedua. UPP STIM YKPN. Yogyakarta.

Widarjono, Agus. 2013. Ekonometrika : Pengantar dan Aplikasinya Disertai Panduan Eviews. Edisi-4. UPP STIM YKPN. Yogyakarta.

Yusral,Y.; Junaidi,J.;Adi Bhakti.(2015). Klasifikasi Pertumbuhan, Sektor Basis dan Kompetitif Kota Jambi Jurnal Perspektif Pembiayaan dan Pembangunan Daerah, 2(4), 209-216 